\title{
GÉNERO, CUERPOS Y DEPORTE: UNA APROXIMACIÓN AL CONTEXTO PROFESIONAL
}

\author{
Sara Rozenwajn Acheroy \\ Universidad de La Laguna \\ srozenwa@ull.es
}

\section{Resumen}

A pesar de ser el deporte un agente socializador y tener una amplia implicación en la política ya que está presente en organismos internacionales como la Oficina del Deporte para el Desarrollo y la Paz de las Naciones Unidas (UNOSDP), la Comisión Europea y en diferentes normativas del ámbito occidental, pocos estudios actuales sobre la sociología del deporte plantean las cuestiones de género en sus metodologías y resultados. En este artículo ofrecemos un estudio de la competición deportiva desde una perspectiva de género para analizar algunos estereotipos y desigualdades entre hombres y mujeres en competiciones como el tenis, boxeo, fútbol y surfing.

Palabras clave: género, deporte, estereotipos de género, educación deportiva.

\section{GENDER, BODIES AND SPORT: AN APPROACH \\ TO THE PROFESSIONAL CONTEXT}

\section{Abstract}

Despite the fact that sport is a socializing agent and has a broad involvement in politics, since it is present in international organizations such as the United Nations Office for Sport for Development and Peace (UNOSDP), the European Commission and in different regulations In the Western world, few current studies on the sociology of sport pose gender issues in their methodologies and results. In this article we offer a study of sports competition from a gender perspective to analyze some stereotypes and inequalities between men and women in competitions such as tennis, boxing, soccer and surfing.

KEYwORDs: gender, sport, gender stereotypes, sport education.

DOI: http://doi.org/10.25145/j.atlantid.2018.09.009

Revista Atrántida, 9; diciembre 2018, pp. 171-182; ISSN: e-2530-853X 


\section{INTRODUCCIÓN}

El deporte, en su configuración actual, reproduce valores culturales y conforma subjetividades e ideales identitarios (Dauder, 2014; Pujadas et al., 2011; García Ferrando et al., 2009; Rodríguez Díaz 2008; Elias y Dunning, 1992; Blanchard y Cheska, 1986). La actividad deportiva constituye en sí misma, además, uno de los principales negocios del mundo contemporáneo globalizado (Ohl, 2015; Duret, 2012; Latiesa et al., 2001; Gasparini, 2000; Durán et al., 1998). Debido a la importancia del deporte como componente de la socialización, elemento de cohesión social y cultural y por su papel en el mercado, los países tienden institucionalizarlo a través de la educación, las federaciones y clubes deportivos, así como la construcción y mantenimiento de espacios deportivos públicos y concertados. En España, las normativas vigentes consideran el deporte como una de las actividades de interés nacional de mayor arraigo y capacidad de movilización (Ley 10/1990, de 15 de octubre, del Deporte, en $B O E 249$ a 17/10/1990). Esta ley sitúa al deporte como un elemento fundamental en el sistema educativo, corrector de desequilibrios sociales, así como una práctica que contribuye a la igualdad. Debido a su gran influencia, la Ley Orgánica para la Igualdad Efectiva de Mujeres y Hombres también incluye referencias explícitas a la necesidad de igualdad en el deporte (Art. 29, LOIEMH 3/2007).

En el marco del análisis del deporte como fenómeno social, la Sociología considera el deporte un fenómeno cuyos límites son difíciles de definir al estar fuertemente integrado en la vida cotidiana y, al igual que el trabajo, fundido con la identidad (Ferrando et al., 2009). Como fenómeno expansivo, se convierte en agente socializador, reproductor de valores y de construcción identitaria de gran relevancia simbólica, ideológica y económica, además de ser un fenómeno cultural internacional y global. Una influencia que no ha pasado desapercibida en la Oficina del Deporte para el Desarrollo y la Paz de las Naciones Unidas (UNOSDP, 2015) ni a la Comisión Europea (2007), que consideran el deporte como una herramienta fundamental para promover la educación, la salud, el desarrollo y la paz.

La práctica deportiva reproduce valores relacionados con el cuerpo, la higiene, el control y, en general, la imagen corpórea, proyectando una epopeya basada en estereotipos de hombres fuertes y viriles y mujeres delgadas y elegantes (Gasparini, 2000; Fasting, 2000; Rodríguez 2008; Duret, 2012;). A su vez, numerosas investigaciones han demostrado que las mujeres experimentan una constante infravaloración en el ámbito deportivo (Fasting et al., 2000; Lantillon, 2009), bien en su práctica diaria, que recrea la idea de que los hombres están mejor dotados para las actividades deportivas por naturaleza, bien en la práctica profesional, donde se evidencia un trato desigual por parte de directivas y federaciones diversas (Fasting, 2000). De igual modo, los progenitores tienden a considerar a sus hijos más competentes que sus hijas en el deporte y estiman más importante la actividad física para el desarrollo del niño que para el de la niña (Lentillon, 2009). Esta baja valoración de las chicas en el deporte hace que estas no se sientan competentes (Fredericks y Eccles, 2005) y tiene repercusiones en su autopercepción, expectativas de futuro, así como en la construcción identitaria (García-Cuesta y Sáinz, 2013). 
Tanto la práctica deportiva reglada como el nivel de participación de las mujeres en la formación de deportistas, así como la percepción social que se tiene de las atribuciones deportivas de hombres y mujeres, indican que hay claros sesgos de género en la consideración del deporte en el contexto inmediato. Siendo esta una actividad tan relevante para la cohesión social y como elemento cultural y de transmisión de valores, entendemos que estos sesgos deben ser investigados a fondo para contribuir a hacer realidad los enunciados normativos a favor de la igualdad en el deporte.

Los resultados que se ofrecen a continuación forman parte de la investigación realizada desde estos parámetros, que fundamentó el Trabajo de Fin de Máster del postgrado en Estudios de Género y Políticas de Igualdad de la Universidad de La Laguna, en el año 2016. El objetivo general de este trabajo fue explorar las relaciones entre la actividad física y/o deportiva y la construcción identitaria de sus imaginarios, desde una perspectiva de género y a través de una metodología multiestratégica para la aproximación a casos concretos.

En el marco de esta finalidad general, los objetivos especificos se centraron en: 1) descubrir algunos aspectos de la desigualdad en el deporte internacional a través del análisis de varias disciplinas: el tenis, la natación, la gimnasia, el rugby, el boxeo y el surf, 2) indagar sobre los discursos del deporte y de la actividad física implicados en la normativización de los cuerpos femeninos y masculinos y 3) analizar las consecuencias de ese discurso en la construcción identitaria y en el imaginario colectivo a través de algunas prácticas con gran relevancia social entre la gente joven, en concreto, una muestra de universitarios/as.

Las presunciones o hipótesis basadas en el análisis teórico previo plantearon que 1) la institucionalización de la actividad física y el deporte tiene un origen androcéntrico y sexista que prevalece hasta hoy en día; 2) el deporte y la actividad física son factores activos y determinantes a la hora de definirse en la sociedad, tanto físicamente como personalmente, esto es, conforman cuerpos, pero también subjetividades; 3) el deporte y la actividad física refuerzan el estereotipo de la mujer como el «sexo débil», ya que su marco constitutivo es binario y opone atributos asociados a la estereotipia de género.

Con el fin de responder a estos objetivos e hipótesis iniciales, se analizó una base bibliográfica amplia y se aplicó una triangulación de técnicas: el análisis comparativo de los premios en dinero de los y las tres primeras deportistas del ranking mundial de seis deportes señalados (tenis, natación, gimnasia, rugby, boxeo y surf); el análisis mediático de las más señaladas representaciones visuales de los y las deportistas a través de Google Imágenes y, finalmente, la realización de una encuesta sobre percepción, prácticas y estereotipos deportivos realizada en la Universidad de La Laguna (2016).

Debido a que los contextos territoriales e históricos influyen en la aproximación de las mujeres al deporte (Fasting et al., 2000), es importante recalcar que cuando hacemos referencia al deporte, el cuerpo y el género, nos remitimos a una concepción contemporánea en las sociedades occidentales europeas (lo cual no excluye la similitud con otros contextos). Aun así, hay que tener en cuenta que el efecto y el acceso no ha sido igual en todos los países y tampoco lo ha sido la percepción 
social de las mujeres y el deporte. La dictadura franquista en España, por ejemplo, retrasó considerablemente la inclusión de las mujeres en el deporte al mismo tiempo que definió de manera diferencial los espacios y las percepciones personales, frente a otros países europeos como Inglaterra o Finlandia.

\section{METODOLOGÍA Y PLAN DE TRABAJO}

El Trabajo Final de Máster desplegó una metodología de análisis multiestratégica que comprendió en primer lugar un análisis de fuentes secundarias de orden cualitativo a través de la revisión bibliográfica con el fin de lograr una aproximación teórico-conceptual para definir y englobar el sexismo y los discursos sobre el cuerpo en el deporte, la importancia del cuerpo como constructor identitario y la influencia del deporte como agente socializador.

En segundo lugar, se analizó el ranking de las y los tres primeros deportistas de cinco deportes de influencia internacional (el tenis, la natación, la gimnasia, el rugby, el boxeo y el surf), así como el impacto mediático en las primeras posiciones de visualización online a través Google Imágenes. Los deportes fueron elegidos según criterios de heterogeneidad en la identificación de género y la participación de las mujeres en los mismos: la gimnasia es valorada socialmente como más femenina y aporta mayor participación de las mujeres, el boxeo y el rugby tienen el mismo efecto para los hombres y, finalmente, el tenis, la natación y el surf se colocan en un posicionamiento intermedio o más neutral ${ }^{1}$.

Una vez contrastados y analizados los datos del ranking mundial, se realizó un análisis de los medios de comunicación utilizando a Google como buscador representativo y como técnica aleatoria porque es un buscador que jerarquiza las páginas web o las imágenes según relevancia. La categorización se realiza teniendo en cuenta la localización, el número de visitas de las páginas y/o la inversión económica. De ese modo, una página web aparecerá en las primeras opciones si es una página con muchas visitas y/o si tiene inversión -ya que Google las favorece en el orden de las búsquedas-. Las páginas web que se encuentran en la primera página del buscador van a ser las más visitadas en el buscador y las más accesibles. Se analizaron las 30 primeras imágenes en Google Imágenes de los y las tres primeras del ranking de cada deporte.

Los criterios de análisis de género se llevaron a cabo teniendo en cuenta 1) la relación que aparece en la imagen de cada deportista con su deporte; por ejemplo, si aparecen las tenistas en las imágenes relacionadas con el tenis o si por el contrario aparecen descontextualizadas en anuncios publicitarios u otros, 2) la existencia de diferencias en la manera de mostrar esa relación con el deporte; por ejemplo, suele haber más imágenes de hombres con trofeos que mujeres y 3) la detección de la exis-

${ }^{1}$ Cuando se hace referencia a estereotipos sociales se trata de una adjudicación subjetiva/ social a la cual se ha llegado atendiendo a los datos de las fichas federativas en España. 
tencia o no de cosificación del cuerpo, entendiendo a esta como la sobreexposición del cuerpo, el cual puede llevar a infravalorar el o la deportista como profesional.

Finalmente, se diseñó una encuesta sobre percepción, prácticas y estereotipos de género en el deporte, para el análisis de algunas cuestiones planteadas en un ámbito cercano: la Universidad de La Laguna (ULL). Esta segunda y exploratoria fase empírica de aproximación al contexto local se basó en un cuestionario online, estructurado con preguntas mayoritariamente cerradas. El objetivo de este sondeo fue conseguir una aproximación sobre la reproducción de estereotipos deportivos en la Universidad de La Laguna, así como una exploración de las prácticas deportivas de las personas encuestadas. El cuestionario online recabó una muestra bastante amplia ( $\mathrm{n}=870$ de N: 22 862, del cual 56\% mujeres y 44\% hombres, porcentajes muy similares a los de la muestra) con un nivel de confianza del $95 \%$; el margen de error es 4’28. La muestra incluye en su mayoría miembros de la ULL $\left(\mathrm{n}_{\mathrm{a}}=819\right)$ y una minoría de personas externas $\left(\mathrm{n}_{\mathrm{b}}=51\right)$.

Con el fin de obtener una muestra lo más amplia posible se realizó en dos ámbitos diferentes: una muestra por conveniencia a través de redes sociales propias, como Facebook pidiendo colaboración con la difusión en otros foros de interés. Se trata aquí más bien de una prueba exploratoria y un pretest, y una segunda muestra realizada en colaboración con la Unidad de Igualdad de Género y el Servicio de Deportes de la Universidad de La Laguna, con una carta institucional con enlace de encuesta dirigida a toda la comunidad universitaria, de modo que esta se dirigió únicamente a personas de la comunidad de la ULL.

\begin{tabular}{l}
\hline \multicolumn{7}{c}{ TABLA 1: HOMBRES Y MUJERES QUE SÍ PRACTICAN ACTIVIDAD FÍSICA. } \\
PUESTO MUNDIAL TENIS POR SEXO, PUNTOS Y TOTAL EN PREMIOS (\$)(11 DE ABRIL 2016) \\
\hline \\
\hline
\end{tabular}

Fuente: elaboración propia a partir de página web oficial ATP y WTA, más Felipe Oliva (2016) y Pedro Gutiérrez (2012).

\section{RESULTADOS}

De acuerdo con los resultados y el análisis realizado en este trabajo y respondiendo a los objetivos formulados y a las hipótesis que se asocian a los mismos, se puede concluir que:

Existe una amplia bibliografía académica y de investigación que ha mostrado que el deporte moderno tiene un origen clasista y sexista, origen que mantiene aún 
prácticas de desigualdad que no han tenido las suficientes respuestas institucionales (Blanchard y Cheska, 1986).

El análisis llevado a cabo del impacto en Google Imágenes lleva a reafirmar la idea de que el deporte es una industria que se rige por un principio lucrativo que funciona particularmente a través de los medios de comunicación masiva (Durán González et al., 1998). El principio del lucro responde a un modelo reproductivo de percepción de los cuerpos y de las deportistas al uso de las referencias androcéntricas vigentes.

La desigualdad en el ámbito profesional es patente en diversos sentidos: a) todas las mujeres en cualquier categoría ganan menos dinero que los hombres del mismo nivel (muestra de premios) b) en todos los deportes nos encontramos con mujeres hipersexualizadas, no siendo el caso de los hombres (muestra imágenes Google) c) la representación del triunfo y la retransmisión de los logros y los méritos es menor en las mujeres campeonas que en los hombres (muestra imágenes Google). Estos indicios invitan a señalar cómo la institucionalización de la actividad física y el deporte mantiene su origen androcéntrico y sexista, que prevalece hasta hoy en día.

El marco teórico y el análisis mediático también han afianzado la segunda presunción, que señala al cuerpo como un cruce interseccional entre la subjetividad y el poder. El culto al cuerpo y el culto a la imagen están integrados socialmente a través de la dominación individual (Foucault, 1992). La respuesta al canon corporal de cuerpo y a la imagen se canaliza también a través del deporte, reflejado en la encuesta realizada en la que el $42 \%$ de quienes practican deporte sienten culpabilidad si no pueden hacerlo, en un marco en el que un $61 \%$ de la muestra practica actividad física tres o más veces a la semana. Una actividad a la que dedican tanto tiempo se convierte inevitablemente en un constructor identitario y de prácticas cotidianas.

Los resultados de la encuesta reflejaron que las mujeres de la muestra practicaron tanto deporte como los hombres y aunque los hombres parecen tener cierta reticencia a las actividades consideradas más femeninas, las mujeres en cambio practican muchas actividades consideradas masculinas. De hecho, un $43 \%$ (frente al $57 \%$ hombres) de las personas que practican actividad física y/o deportiva de fuerza, resistencia y/o riesgo (Grupo 2) son mujeres, ocupando el tercer puesto de las actividades más practicadas por las mujeres $(21,30 \%)$.

Resulta curioso observar cómo el comportamiento que señalan las mujeres en la muestra realizada en la ULL lleva la contraria al imaginario social estereotipado sobre las mujeres en el deporte. A la vista de estos resultados muy centrados en la comunidad académica $(n=870)$, es posible que las mujeres estén practicando cada vez más actividades que no "corresponden" a su sexo (estereotipia) y tal vez sean los medios de comunicación los que no estén reflejando y valorando el deporte femenino fuera del contexto asignado por dicha esterotipia. Asimismo, ocurre que a menudo la desigualdad es más institucional que social; por ejemplo, los individuos encuestados consideran que la mayoría de los deportes son propios de ambos sexos. Sin embargo, a pesar de que la ULL intente aplicar cierta perspectiva de género en el deporte, sigue sin haber algunos deportes y campeonatos mixtos, $\mathrm{o}$, incluso, sigue habiendo actividades deportivas en las que no pueden entrenar 
mujeres, ya que no existe la categoría. Añadimos a lo anterior que pueden existir barreras de género como los horarios, e instalaciones que favorecen las actividades más masculinizadas.

Añadido a esto y como se ha observado en este análisis respondiendo a la tercera hipótesis, la desigualdad en las instituciones internacionales es muy fuerte a nivel profesional específicamente en la distribución de los premios y en la presentación de la imagen pública de las y los deportistas.

\section{DISCUSIÓN}

Los medios de comunicación refuerzan los estereotipos y el binomio sexista al no valorar y presentar de la misma manera las campeonas y campeones de los deportes analizados. Puede estar habiendo una distancia importante entre las prácticas deportivas reales de la población y la imagen que de estas ofrecen estos medios. No obstante, junto con la evidencia de sangrantes desigualdades en los premios deportivos, una reciente polémica en el tenis muestra la gran reticencia a la inclusión y reconocimiento de las mujeres como iguales en el deporte profesional ${ }^{2}$. En el ámbito institucional destacan los test genéticos y hormonales de género realizados a mujeres deportistas, éticamente muy cuestionables. Dudar del potencial de las mujeres justificando una ventaja competitiva masculina innata implica una minusvaloración de las deportistas. Las instituciones deportivas no actúan frente a la cosificación y la representación estereotipada de la mujer supuestamente débil, permitiendo a su vez la propagación de una cultura del desnudo femenino sexualizado de las deportistas, frente a una sobrevaloración del éxito masculino fundamentado en los estereotipos de fuerza, competitividad y potencia. De ese modo, los valores sexistas interiorizados por campeones como Djokovich culminan en una ridiculización de sus contemporáneas ${ }^{3}$. Del mismo modo que a las boxeadoras o a las surfistas analizadas no les bastaron sus títulos mundiales para obtener las mismas cuantías en premios y el mismo reconocimiento mediático que cualquier otro boxeador o surfista varón del top 10 .

El sexismo en el deporte está vinculado a muchos factores: el interés de las marcas, instituciones privadas y públicas, medios de comunicación, entre otros. Los elementos culturales (estereotipos) y la desigualdad de género estructural forman parte de un sistema de producción y de una maquinaria organizada para maximizar dicho beneficio. Cualquier elemento o variación que perturbe este orden, no va a ser fácilmente incorporado. Con este trabajo se pone de manifiesto la necesidad de una línea de investigación e intervención en el ámbito deportivo desde las políticas

${ }^{2}$ El caso mencionado de Novak Djokovic que denigra públicamente las capacidades de la liga femenina de Tenis. Disponible en la web, 20 de abril 2016: http://ecodiario.eleconomista.es/ tenis/noticias/7436398/03/16/Djokovic-sexista-En-tenis-los-hombres-deberian-ganar-mas-que-lasmujeres.html.

${ }^{3}$ Leer nota 2. 
de igualdad de género y desde las políticas de igualdad de oportunidades en general, respondiendo además a los imperativos de la legislación de igualdad y que profundice en cuestiones que no han ocupado la atención académica.

Recibido: 29-1-2018; aceptado: 21-6-18 


\section{BIBLIOGRAFÍA}

Blanchard, K. y Cheska, A. (1986). Antropología del deporte. Barcelona: Ediciones Bellaterra.

Durán González, J., García Ferrando, M. y Latiesa Rodríguez, M. (2009). «El deporte mediático y la mercantilización del deporte; la dialéctica del deporte de alto nivel», en M. García Ferrando, N. Puig Barata y F. Lagardera Otero, et al. Sociología del deporte. Madrid: siglo XXI, pp. 205-230.

Duret, P. (2012). Sociologie du Sport. Paris: Presses Universitaires de France.

Elias, N. y Dunning, E. (1992). Deporte y ocio en el proceso de la civilización. Madrid: Fondo de Cultura Económica.

Fasting, K., Scraton, S., Pfister, G., Vázquez, B. y Buñuel, B. (2000). Experiencia y significado del ejercicio físico en la vida de las mujeres de algunos paises europeos. Madrid: Instituto de la Mujer.

Fredericks, J.A. y Eccles, J.S. (2005). «Family socialization, gender, and sport motivation and involvement». Journal of sport and exercise psychology, 27, pp. 3-31.

García Cuesta, S. y SÁinz, M. (2013). «¿Qué espera el profesorado de secundaria del alumnado? Expectativas y estereotipos de género sobre las asignaturas de ciencias, tecnología, informática, lengua en España», en H. Cairo y L. Finkel. Crisis y cambio. Propuestas desde la Sociología, volumen I. Actas del XI Congreso Español de Sociología, pp. 1546-1557.

García Dauder, S (2014). «Capítulo X. La Regulación Tecnológica del Dualismo sexual y el diseño de cuerpos normativos», en E. Pérez Sedeño y E. Ortega Arjonilla (eds.), Cartografía del Cuerpo; biopolíticas de la ciencia y la tecnología, Valencia: Ediciones Cátedra Universitat de València, pp. 469-520.

García Ferrando, M., Puig Barata, N. y Lagardera Otero, F. (comps.), (2009) Sociología del deporte, Madrid: Alianza Editorial.

García Muñoz, T. (2003) El cuestionario como instrumento de investigación/evaluación, Almendralejo, Espańa. Disponible en: http://www.univsantana.com/sociologia/El_Cuestionario.pdf.

Gasparini, W. (2000). Sociologie de l'organisation sportive. Paris: éditions La Découverte.

Informe Parlamento Europeo (2003). sobre mujeres y el deporte. Comisión de Derechos de la Mujer e Igualdad de Oportunidades, n. ${ }^{\circ} 2280$.

Latiesa Rodriguez, M., Martos Fernández, P. y Paniza Prados, J.L., (2001). «Deporte y cambio social en el umbral del siglo XXI». Investigación Social y Deporte n. ${ }^{\circ}$ 5. Consejo Superior de Deportes.

Lentillon, V. (2009). «Les stéréotypes sexués relatifs á la pratique des activités physiques et sportives chez les adolescents français et leurs conséquences discriminatoires». Bulletin de psychologie, 1, n. ${ }^{\circ}$ 499, pp. 15-28. DOI 10.3917/bupsy.499.0015.

Ley 10/1990 del Deporte (1990). BOE 249 de 17/10/1990. Disponible en la web: https://boe.es/ buscar/act.php?id=BOE-A-1990-25037.

Ley Orgánica 3/2007 para la Igualdad Efectiva entre Mujeres y Hombres (2007). BOE 71 a 23/03/2007. Disponible en la web: https://www.boe.es/buscar/act.php?id=BOE-A-2007-6115.

OHL, F. (2015). Sociologie du sport: perspective internationales et mondialization. Paris: Presses Universitaires en France. 
Pujadas, X. (coord.) (2011). Atletas y Ciudadanos: historia social del deporte en España 1870-2010. Madrid: Alianza Editorial Consejo Superior de Deportes.

Rodríguez Díaz, A. (2008). El deporte en la construcción del espacio social. Madrid: Centro de Investigaciones Sociológicas, Monografías n. ${ }^{\circ} 261$.

UNOSDP (2015). United Nations Office on Sport for Development and Peace (2016). Annual Report Disponible en https://www.un.org/sport/sites/www.un.org.sport/files/ckfiles/files/ UNOSDP_Annual_Report_2015\%20(1).pdf. 


\section{ANEXOS}

Cuadros de los premios, cuadros de los análisis mediáticos e imágenes en modo ejemplo.

\begin{tabular}{cccc}
\hline Deportes & Rankings & Media de premios en \$ & Diferencia \\
\hline \multirow{2}{*}{ Tenis } & Mujeres & $\$ 48497,96$ & \\
\cline { 2 - 4 } & Hombres & $\$ 90821,44$ & $\$ 423,48$ \\
\hline
\end{tabular}

\section{TABLA 2: ANÁLISIS MEDIÁTICO TENIS SEGÚN SEXO Y RANKING}

\begin{tabular}{|c|c|c|c|c|c|c|}
\hline \multirow[b]{2}{*}{ Número de veces que... } & \multicolumn{3}{|c|}{ Tenis Femenino } & \multicolumn{3}{|c|}{ Tenis Masculino } \\
\hline & $\begin{array}{c}\text { Serena } \\
\text { Williams }\end{array}$ & $\begin{array}{c}\text { Maria } \\
\text { Sharapova }\end{array}$ & $\begin{array}{c}\text { Venus } \\
\text { Williams }\end{array}$ & $\begin{array}{c}\text { Novak } \\
\text { Djokovic }\end{array}$ & $\begin{array}{l}\text { Roger } \\
\text { Federer }\end{array}$ & $\begin{array}{l}\text { Rafael } \\
\text { Nadal }\end{array}$ \\
\hline $\begin{array}{l}\text { Aparece relacionada/o } \\
\text { con el tenis (en el campo } \\
\text { de tenis, en medio de un } \\
\text { torneo, con la pala, etc.) }\end{array}$ & 18 & 3 & 22 & 24 & 28 & 27 \\
\hline Aparece con una copa & 7 & 1 & 1 & 3 & 1 & 1 \\
\hline $\begin{array}{l}\text { Aparece sexualizada/o o } \\
\text { con sobreexposición del } \\
\text { cuerpo }\end{array}$ & 2 & 3 & 0 & 0 & 0 & 0 \\
\hline $\begin{array}{l}\text { Neutra (no relacionada/o } \\
\text { con su deporte pero tam- } \\
\text { poco sexualizada/o) }\end{array}$ & 3 & 23 & 7 & 3 & 1 & 2 \\
\hline TOTAL & 30 & 30 & 30 & 30 & 30 & 30 \\
\hline
\end{tabular}

Fuente: elaboración propia desde Google Imágenes. Marzo 2016. 
FOTOS
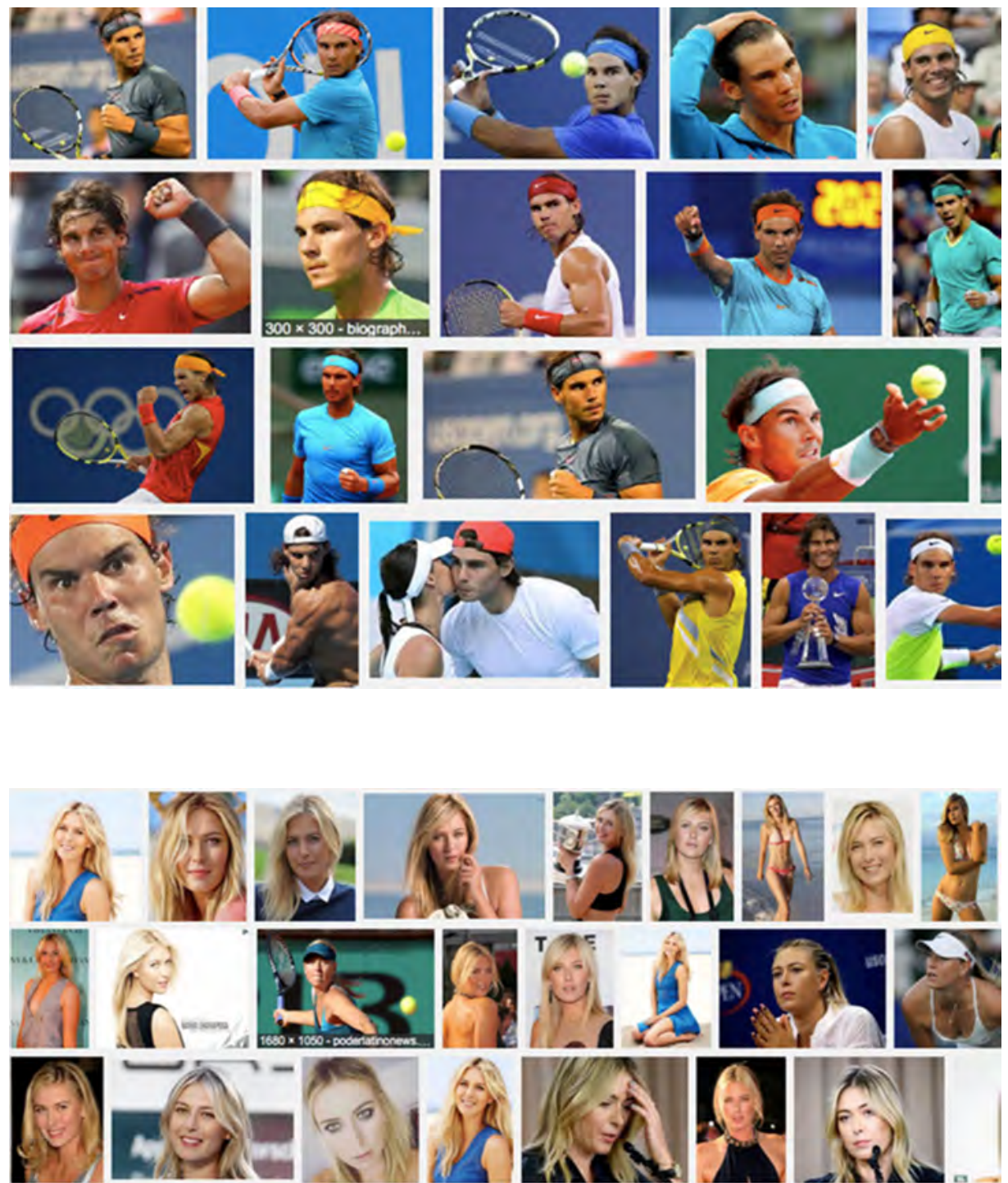